Special issue of the 2nd International Conference on Computational and Experimental Science and Engineering (ICCESEN 2015)

\title{
Trace Metals Contamination of Bottom Sediments of Abu Dhabi Area, UAE
}

\author{
M. El Tokhi*, B.M. Amin and S. AlaAbed \\ UAE University, Geology Department, Al Ain, United Arab Emirates
}

\begin{abstract}
Seventy nine bottom sediment samples were collected from Abu Dhabi area from Ghantoout area in the north east from $\mathrm{Abu} \mathrm{Al} \mathrm{Abyad} \mathrm{island} \mathrm{to} \mathrm{determine} \mathrm{the} \mathrm{regional} \mathrm{distribution} \mathrm{of} \mathrm{concentration} \mathrm{of} \mathrm{trace} \mathrm{metals} \mathrm{and}$ pollution levels in the studied area. In general, a negative correlation has been reported between trace metals concentration and total organic matter with the exception of $\mathrm{Cu}, \mathrm{Zn}$, Co and $\mathrm{Cr}$. A negative relation between trace metals concentrations and carbonate content was also found in the area of study. The present study focuses on the levels of copper, lead, iron, manganese, nickel, cadmium, zinc and vanadium in order to assess the extent of the environmental pollution and to discuss the origin of these contaminants in the sediments. The average concentrations of copper, zinc, lead, iron, manganese nickel, cadmium and vanadium are 4.65, 11.94, 1.91, 2800, $92.26,10.55,0.082$ and $11.43 \mu \mathrm{g} / \mathrm{g}$ respectively. These values are within the permitted levels in the marine activity areas and industrial activity areas, which means that trace metals are not derived from the pollutant sources.
\end{abstract}

DOI: 10.12693/APhysPolA.130.138

PACS/topics: 91.62.Rt, 92.20.Ny

\section{Introduction}

The United Arab Emirates (UAE) are situated at the southern part of the Arabian Gulf (Fig. 1). They extend from the Qatar peninsula to Oman over a distance of $725 \mathrm{~km}$ along the Arabian Gulf coast. Additional $76 \mathrm{~km}$ of the Eastern coast borders, immediately south the Musandam Peninsula, with the Sultanate of Oman [1]. The Arabian Gulf coastal sector is a low-lying area of extensive tidal flats, lagoons and sand dunes, while the Eastern coastal area is mountainous $[2,3]$.

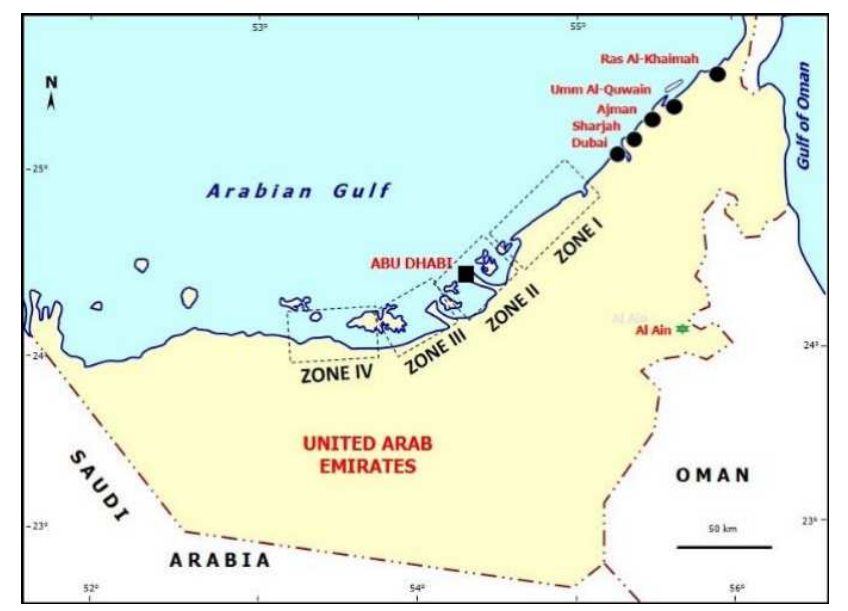

Fig. 1. Location map oh the area of study.

Overall, the coastal region of the UAE can be divided into the Arabian Gulf coastal region (area of study) and the eastern coast of UAE region (Oman Gulf).

\footnotetext{
*corresponding author; e-mail: meltokhi@uaeu.ac.ae
}

\section{Description of the studied area}

The UAE are located on the eastern side of the Arabian Peninsula, between latitudes $22^{\circ} 40^{\prime}$ and $26^{\circ} 00^{\prime}$ North, and longitudes $51^{\circ} 00^{\prime}$ and $56^{\circ} 00^{\prime}$ East, where the interior platform of the Arabian shelf occurs in the subsurface. It is bounded in the northwest by the Qatar-South Fars Arch, and in the northeast and east by the foreland basin of the Arabian Gulf, and adjacent foreland fold and thrust belt of Oman (Fig. 1).

The study area is located in the UAE, in the offshore of the Abu Dhabi area of the Arabian Gulf, approximately $120 \mathrm{~km}$ from Gantoout area in the north east to $\mathrm{Abu} \mathrm{Al}$ Abyad island. We have found that the concentrations of trace metals in the bottom sediments vary between different locations in the studied area.

Therefore, we have identified four zones (Zone I: from Gantoout area to Khor al Baghi, Zone II: from to Khor al Baghi to Khor al Batin, Zone III: from Khor al Batin to end of al Dhabaiya area and Zone IV: from al Dhabaiya area to Abu Al Abyad island (Fig. 1). They include a nearly closed lagoon connected to the Arabian Gulf by narrow channels, and are being enveloped by a large sabkha, constituting the supratidal part of the lagoon [4]. To the southwest, along the coast of the UAE, barrier islands become numerous and widespread and include Abu Dhabi, Al Sadiyat, Al Qanatir, Abu Al Abyad, and Marawwah (Fig. 1). These islands and the peninsula of Al Dhabaiya are nucleated around Pleistocene aeolian calcareous sands and marine sediments, which are locally elevated some 2 to $4 \mathrm{~m}$ above sea level [5].

\section{Experimental study 3.1 Hydrographic survey}

Some physicochemical parameters e.g. $\mathrm{Ph}$, dissolved oxygen, salinity, temperature and depth were measured in situ using the water quality logger, whereas the locations were determined using GPS. 


\subsection{Sampling}

In most aquatic systems, the concentrations of the trace metals in the bottom sediments are much greater than their concentrations in the water column. Bottom sediments are known to act as a reservoir or sink for many trace metals and some other pollution. The studied areas are located in the Arabian Gulf between Gantoout area $24^{\circ} 53^{\prime} 48.5^{\prime \prime}$ North and Abu Al Abyad island $54^{\circ} 50^{\prime} 0.3^{\prime \prime}$ East. Seventy-nine sediment samples (of one kilogram) were collected from the bottom of the Arabian Gulf, from the depth of 6 to $10 \mathrm{~m}$, in order to trace the pollution level of these sediments by using the mineralogical and geochemical analyses. Samples were collected by using driver and grab sampler, using GPS to determine the coordinates of each station and were immediately transferred into sampling containers. The sampling containers were immediately sealed, labeled, refrigerated and kept frozen prior to chemical and physical analyses. In the laboratory, the collected samples were dried and sieved for grain size analysis and for the measurement of heavy metals concentrations.

\subsection{Laboratory analyses}

Laboratory analyses carried out for the bottom sediments of the Arabian Gulf include grain size analysis and trace metals concentration measurement.

\section{Results}

The statistical parameters of the grain size were determined according to [6]. Mean size of samples taken from, Zone I to Zone IV indicate that these areas are covered mainly by coarse to fine sand (Fig. 2).
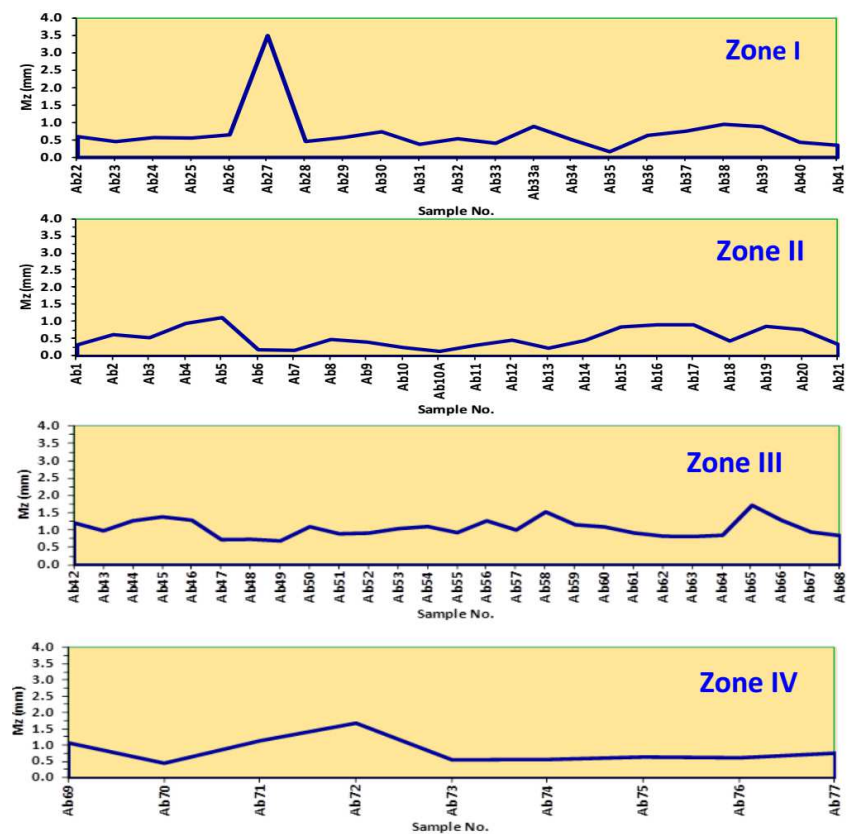

Fig. 2. Mean grain size in the studied area.

\subsection{Trace elements and organic matter and carbonate relationship}

In the bottom sediments, the organic matter and carbonate contents have a relationship with the concentrations of trace elements [7]. In general, negative correlation is found between trace metals concentrations and total organic matter, with the exception of $\mathrm{Cu}, \mathrm{Zn}$, Co and Cr. A negative relation between trace metals concentrations and carbonate content was found in the studied area (Table I). Bryan has suggested that the sedimentological characteristics of bottom sediments in the Arabian Gulf reflect the interaction between autochthonous calcareous fragments, mostly of biogenic origin, rock fragments derived from beach rocks and submerged reef flats, and allochthonous terrigenous detritus, supplied to the area mainly by dust storms and river deltas in the far northern area and along the Iranian side [8]. Others have used carbonate $\left(\mathrm{CaCO}_{3}\right)$ measurements made on the whole core sediment samples [9] to draw a map showing the regional distribution of carbonates in the Gulf. All trace metals tend to be concentrated in bottom sediments with low carbonate contents throughout the Arabian Gulf.

\section{TABLE I}

Average total carbonate content (TCC) and total organic matter (TOM) content in different zones in Abu Dhabi bottom sediments.

\begin{tabular}{c|c|c|c}
\hline \hline Zone & Samples No. & TCC & TOM \\
\hline Zone I & Ab.1 - Ab.20 & 85.83 & 4.4 \\
Zone II & Ab.21 - Ab.41 & 82.85 & 2.70 \\
Zone III & Ab.42 - Ab.69 & 79.64 & 7.70 \\
Zone IV & Ab.70 - Ab.77 & 89.96 & 3.70
\end{tabular}

\subsection{Trace metals concentration}

Seventy nine bottom sediment samples of Abu Dhabi area were submitted to trace element analysis. Concentrations of heavy metals $(\mathrm{Cd}, \mathrm{Co}, \mathrm{Cr}, \mathrm{Cu}, \mathrm{Fe}, \mathrm{Mn}, \mathrm{Ni}, \mathrm{Pb}$, $\mathrm{V}$ and $\mathrm{Zn}$ ) (Table II) were determined in an aliquot using inductively coupled plasma-mass spectrometry (ICPMS) at Acme Labs, Canada. Along with the samples, system and method blanks were run with standard material for background correction and quality control.

TABLE II

Average content (\%) of trace metals in Abu Dhabi bottom sediments.

\begin{tabular}{c|c|c|c|c|c|c|c|c|c|c|c}
\hline \hline Zone & $\mathrm{Cu}$ & $\mathrm{Pb}$ & $\mathrm{Zn}$ & $\mathrm{Ni}$ & $\mathrm{Mn}$ & $\mathrm{Fe}$ & $\mathrm{Cd}$ & $\mathrm{V}$ & $\mathrm{Co}$ & $\mathrm{Cr}$ & $\mathrm{Al}$ \\
\hline $\mathrm{I}$ & 3.06 & 1.08 & 4.47 & 5.53 & 54.19 & 0.16 & 0.06 & 7.33 & 1.16 & 15.84 & 0.39 \\
II & 7.66 & 2.48 & 12.25 & 14.30 & 103.05 & 0.33 & 0.08 & 13.05 & 1.16 & 15.84 & 0.78 \\
III & 5.80 & 2.51 & 27.06 & 14.78 & 129.82 & 0.41 & 0.12 & 15.70 & 1.36 & 18.40 & 1.10 \\
IV & 2.09 & 1.56 & 3.96 & 7.60 & 82.00 & 0.22 & 0.07 & 9.63 & 1.43 & 20.04 & 0.69
\end{tabular}

Trace metals are natural constituents of all environments and are found in the seawater, marine organisms and sediments [10]. Therefore, knowing their natural background levels, or at least their permanent concentrations in a marine environment, is essential for detecting and assessing trace metal pollution [11]. 
Trace metals are one of the most important factors among many others in biosphere pollution. Great interest for trace metals results mainly from the serious dangers which are created with the increase of their quantities. After exceeding a definite barrier of their concentration they start to act inhibitively or quite toxically on the growth and metabolic processes of animal and plant organisms.
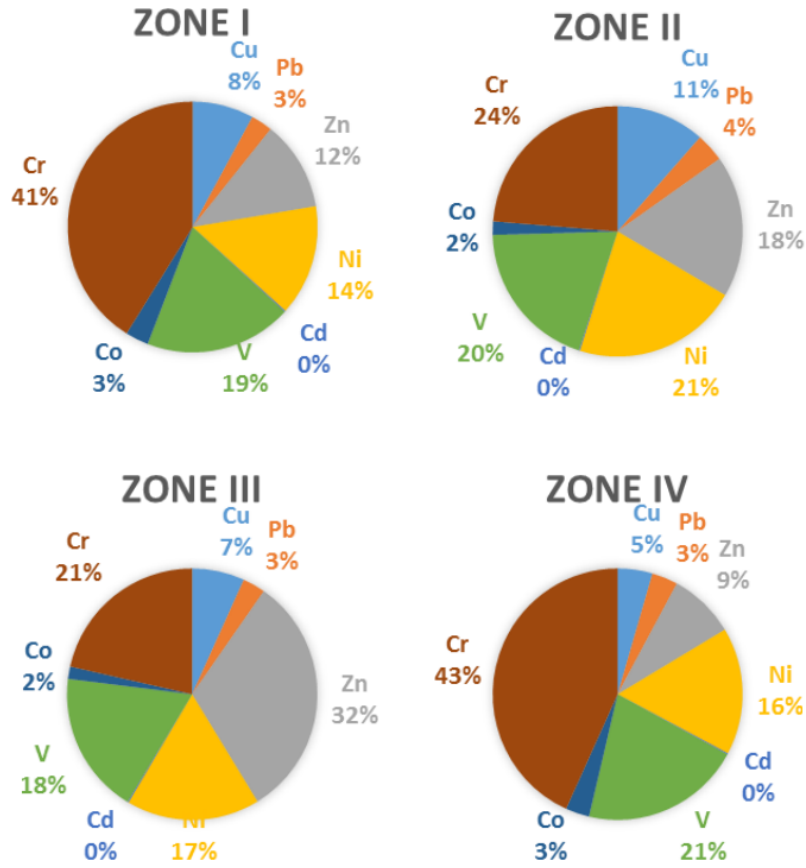

Fig. 3. Concentration (\%) of the trace metals in the bottom sediments of studied area.

Table II shows the analysis of the bottom sediment samples of the studied areas. The average concentrations of copper, zinc, lead, iron, manganese nickel, cadmium and vanadium are 4.65, 11.94, 1.91, 2800, 92.26, $10.55,0.082$ and $11.43 \mu \mathrm{g} / \mathrm{g}$, respectively. These values are within the permitted levels, which means that no elements were derived from pollutant sources. Vanadium and nickel are the largest trace metal constituents of crude oil [12] and hence their presence in high concentration in marine sediments may indicate direct input from oil pollutants. In the studied area the average ratio of $\mathrm{Ni} / \mathrm{V}$ is very low (1.08), indicating no evidence of oil pollution. Figure 3 represents the concentration percentage of different trace metals in different zones of the studied area. It is clear that bottom sediments from Zone II and Zone III have a high concentration of most of the trace metals due to presence of many industrial activity areas. These are followed by Zone I, due to the presence of some marine activity. On the other hand, in Zone IV bottom sediments have the lowest concentration of trace metals due to low population and limited industry activities compared to other studied areas.

Table III gives a summary of the concentrations recorded in unpolluted sediments as guidelines for the

\section{TABLE III}

The comparison between average content $[\mu \mathrm{g} / \mathrm{g}]$ of the trace elements in the Arabian Gulf and in studied areas.

\begin{tabular}{c|c|c}
\hline \hline Trace elements & $\begin{array}{c}\text { Average } \\
\text { (Arabian Gulf) }\end{array}$ & $\begin{array}{c}\text { Average } \\
\text { (studied areas) }\end{array}$ \\
\hline $\mathrm{Zn}$ & $30-60$ & 11.94 \\
$\mathrm{~Pb}$ & $15-30$ & 1.91 \\
$\mathrm{Cd}$ & $1.2-2.0$ & 0.08 \\
$\mathrm{Ni}$ & $70-80$ & 10.55 \\
$\mathrm{Mn}$ & $300-600$ & 92.26 \\
$\mathrm{Fe}$ & $10000-20000$ & 2800 \\
$\mathrm{~V}$ & $20-30$ & 11.43 \\
$\mathrm{Cu}$ & 15300 & 4650
\end{tabular}

natural background levels (upper limits) in the dry, siltclay fraction of unpolluted bottom sediments in the Arabian region (northeastern Kuwait, Saudi Arabian, Iran, Bahrain, Qatar and UAE) in the comparison to the results from the studied area. The average values of the trace elements in the Arabian Gulf were calculated $[13,14]$ and compared with the results obtained in the present study of the bottom sediments in the offshore areas of the UAE (Fig. 4).
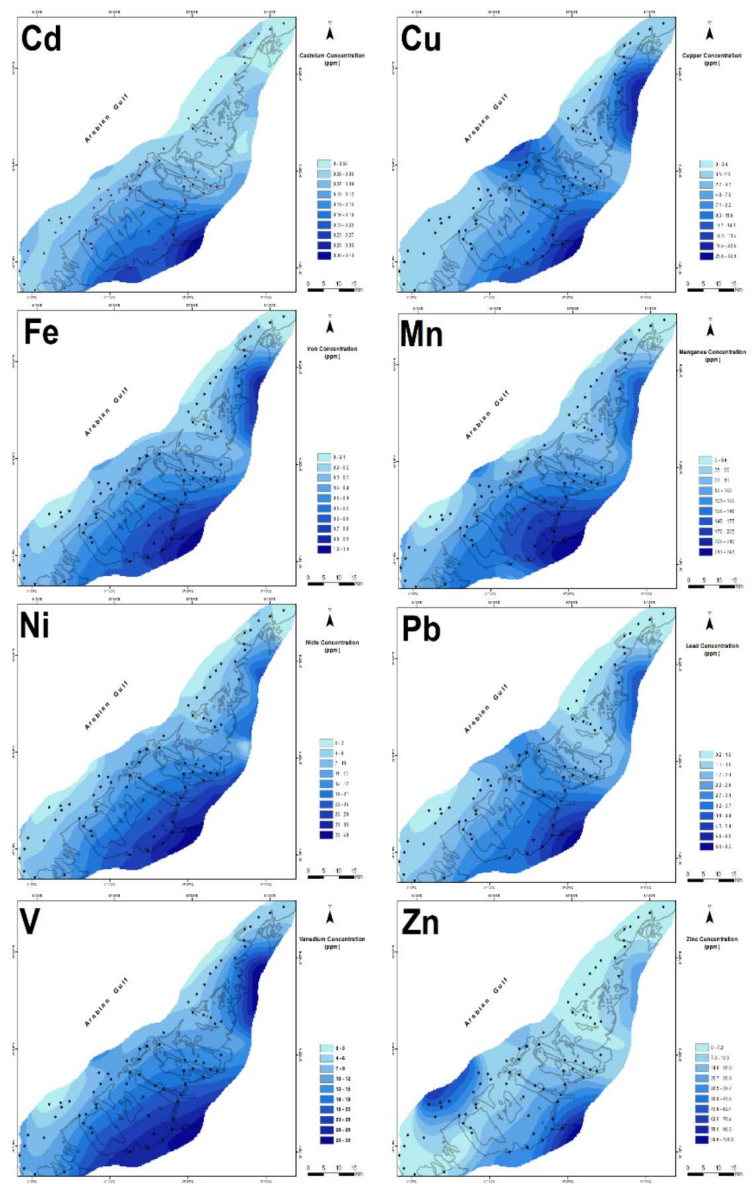

Fig. 4. Distribution patterns of trace metals in the studied area $(\mu \mathrm{g} / \mathrm{g})$. 


\section{Conclusions}

The most of the studied bottom sediment samples range in grain size from sandy mud to muddy sand. The sand and the gravels are restricted to the tidal and near shore line. The moderately to well sorted sandy mud occupies most of the offshore bottom sediments. A well defined relationship between the grain size of the bottom sediment and the trace metals concentration was achieved. The analyzed trace elements have revealed concentration values that are within the permitted range, which indicates that there is no a significant pollution effect in the area of study.

\section{Acknowledgments}

This work was financially supported by the UAEU Program for Advanced Research (UPAR). Project no. 25221, College of Science, UAEU, UAE.

\section{References}

[1] R.J. Hornaby, N.S. Thomas, B.N. Tomlinson, Coastal survey of the United Arab Emirates, unpublished Report, 1996, p. 56 (in Arabic).

[2] UNEPIIUCN, Coral reefs of the world, Indian Ocean, Red and Gulf, vol. 2, UNEP Regional Seas Directories and Bibliographies, IUCN, Nairobi, Kenya 1988, p. 385.

[3] N.S. Embabbi, F.M. Sharkawi, in: Landform systems of The United Arab Emirates. First Symposium on remote sensing in The United Arab Emirates, UAE University, 1989, p. 456.
[4] B.H. Purser, G. Evans in: The Persian Gulf, Holocene Carbonate Sedimentation in a Shallow Epeiric Continental Sea, Ed. B.H. Purser, Springer, New York 1973, p. 211.

[5] A.S. Alsharhan, A.A. El-Sammak, J. Coastal Res. 20, 464 (2004).

[6] R.L. Folk, W. Ward, J. Sediment. Petrol. 27, 3 (1957).

[7] A.J. Horowitz, A Primer on Sediment-Trace Element Chemistry, 2nd ed., Lewis Publishers, Chelsea MI 1991, p. 136.

[8] A.N. Al-Ghadban, M.S. Massoud, F. Al-Abdali, J. Univ. Kuwait 23, 71 (1996).

[9] A.N. Al-Ghadban, P.G. Jacob, Textural Characteristics of ROPNE Sea Area Bottom Sediment. Technical Report, Kuwait Institute for Scientific Research, Kuwait 1993.

[10] E. Jenne, in: Symp. on Molubdenum 2, Eds. W. Chappell, K. Peterson, Marcel-Dekker, NY, USA 1976, p. 425.

[11] G.W. Bryan, Helgoländer Meeresuntersuchungen 33, $6(1980)$

[12] V.C. Anderlini, O.S. Mohammad, M.A. Zarba, R.A. Awayes, R. Al Jalili, in: Marine Environment and Pollution, Proc. of the First Arabian Gulf Conf., on Environment and Pollution, Kuwait 1982, Eds. R. Halwagy, D. Clayton, M. Behbehani, Kuwait University, Faculty of Science, KFAS and EPC, Kuwait 1986, p. 133

[13] B.M. El Tokhi, S. Alaabed, Acta Phys. Pol. A 128, B-103 (2015).

[14] F. Al-Abdali, M.S. Massoud, A.N. Al-Ghadban, Environ. Pollut. 93, 285 (1996). 